\title{
Correction to: Re-examining digoxin bioavailability after half a century: Time for changes in the bioavailability concepts
}

Athanasios A. Tsekouras ${ }^{1,2}$ - Panos Macheras 2,3

Published online: 3 December 2021

(C) Springer Science+Business Media, LLC, part of Springer Nature 2021

Correction to: Pharmaceutical Research volume 38, pages1635-1638 (2021)

https://doi.org/10.1007/s11095-021-03121-w

The references in the article have been renumbered and the reference list has been updated.

The original article has been corrected.

Publisher's note Springer Nature remains neutral with regard to jurisdictional claims in published maps and institutional affiliations.

The original article can be found online at https://doi.org/ 10.1007/s11095-021-03121-w.

Panos Macheras

macheras@pharm.uoa.gr

1 Department of Chemistry, Laboratory of Physical Chemistry, National and Kapodistrian University of Athens, Athens, Greece

2 PharmaInformatics Unit, Research Center ATHENA, Athens, Greece

3 Faculty of Pharmacy, Laboratory of Biopharmaceutics Pharmacokinetics, National and Kapodistrian University of Athens, Athens, Greece 